\title{
Religion: The WEIRDest concept in the world?
}

\author{
Aaron D. Lightner ${ }^{1}$, Zachary H. Garfield ${ }^{1,2}$, and Edward H. Hagen ${ }^{1}$ \\ ${ }^{1}$ Department of Anthropology, Washington State University \\ ${ }^{2}$ Institute for Advanced Study in Toulouse, Toulouse, France
}

June 1, 2021

\section{Introduction}

After a long hiatus, grand theory in anthropology is back. From the second half of the 19th century through first half of the 20th, anthropologists aimed to develop overarching theories of human cultural variation, from the early evolutionism of Tylor and Morgan to the functionalism of Malinowski to the cultural ecology of Steward. One by one, however, these theories failed. Fleeing the conceptual wreckage, many anthropologists disavowed grand theory, turning inward to produce highly particular accounts of specific populations, or to pillory anthropology itself. Predictably, anthropology's scientific influence waned (Spiro, 1992).

Anthropology's subject matter, though, was too scientifically important to ignore. As the 20th century drew to a close, Jared Diamond, an outsider, put forward a materialist grand theory in Guns, Germs, and Steel that rooted economic disparities between the West and the 'Other' in the luck of the ecological draw: domesticatable species in a longitudinally extensive temperate continent, Eurasia, gave its inhabitants a leg up over those in Africa, Australia, and the Americas in developing large, innovative nation-states (Diamond, 1997).

If Guns, Germs, and Steel revived materialist grand theory, then anthropologist Joseph Henrich's The WEIRDest People in the World is its ideational counterpart. Henrich credits Guns, Germs, and Steel for his initial interest in cross-cultural differences in prosperity, and in his comprehensive and thought-provoking book, Henrich (2020) presents a variety of cultural evolutionary theories to explain how Western societies became psychologically peculiar and affluent. His is ultimately an account of the cultural evolutionary success of one unusual family of religious movements and institutions - the Catholic Church and the Protestant Reformation - whose suites of beliefs and practices shaped Western minds over the course of several centuries.

We have been conducting extensive investigations of the ethnographic literature on the roles and functions of leaders and knowledge specialists across cultures, many of whom are part of religious institutions - the universalizing "launchpads" that, according to Henrich, have taken over the world in some form or another (p. 151). Our results speak to an ongoing discussion about the evolutionary origins of religion. Some of our results support Henrich, for whom religious institutions have been a powerful evolutionary force from the "fog of prehistory" onward (p. 127), playing a causal role in shaping behavior and psychology, and having downstream effects on socioeconomic and ecological practices. Religion, according to this view, culturally evolved to promote collective action and other group-level advantages.

Other results of ours, though, support the Boyer (2020) "wild religions" view that in many cultures there are no religious institutions in the sense that Henrich describes. Instead, there are a variety of ideas that Westerners tend to label "religious" that are better understood as cognitively attractive explanations employed by specialists to help others (Bloch, 2008: Boyer, 2016, Sperber, 2018). "Religious" ideas, in other words, are those that resemble Western religious ideas to Western observers, whereas these same ideas, as understood by members of societies in which they originated, are simply part and parcel of larger explanatory frameworks for understanding the world. The 
challenge, which we take up later, is to understand why the human brain, relentlessly optimized by natural selection to further survival and reproduction, would entertain such false explanations.

We expand on these perspectives in the following ways. In section 2 , we critically discuss Henrich's account of religions. In section 3 , we propose our own view, which is complementary to Henrich's account in some cases, and to the alternative "wild religions" perspective in others: In some cases, religious leaders and knowledge specialists serve as prestigious teachers, mentors, and exemplars of cooperative norms, as Henrich describes. In many other cases, though, leaders and knowledge specialists deploy "supernatural" ideas to provide pragmatic services to their communities (Hagen and Garfield, 2019; Garfield et al., 2019). The key distinction, we argue, is that Henrich's model applies mostly to common, everyday problems, such as subsistence and collective actions, whereas the "wild religions" model applies mostly to rare and uncertain phenomena (Lightner et al. 2021a). We conclude in section 4 by considering why Western ethnographers might tend to interpret these practical services as religious institutions, arguing that theories of "religions" might ironically reflect the WEIRD mindset Henrich describes in his book.

\section{Religious institutions: their ingredients and cultural func- tions}

One of anthropology's rejected grand theories is that societies are like organisms: religions, marriage systems, and other social institutions exist because they serve the survival and reproduction of the society (Kroeber, 1917). Henrich and other cultural evolutionists are reviving this theory using analogies from evolutionary biology: groups, like organisms, compete with other groups for resources, with different group-specific ideas playing the role of genetic variants. Intergroup competition, one of three main ingredients that Henrich uses to explain Western prosperity, is the trial and error stage of cultural evolution that tinkers with a proliferation of different beliefs and practices. For Henrich, moralizing gods that punished rule-breakers were a key innovation in this cultural evolutionary process that enabled Western societies to cooperate at large scales, and therefore outcompete other societies (p. 127):

If you are WEIRD, you may think that religion always involves morally concerned gods who exhort people to behave properly, ... [but] the character of gods, afterlives, rituals, and universal morality common to today's world religions is unusual, the product of long-running cultural evolutionary processes.

This cultural evolutionary account depends on two other ingredients, two properties of human cognition that evolved by genetic natural selection. Faith instincts are our evolved tendencies to rely heavily on social learning over individual learning or other sources of information. Social learning requires trust in the testimony of others, especially trust in common beliefs or beliefs espoused by highly regarded individuals, which evolutionary anthropologists will recognize as the conformist and prestige learning biases long emphasized by one camp of cultural evolutionary theorists (e.g., Henrich and Boyd, 1998; Henrich and Gil-White, 2001, Richerson and Boyd, 2008). Genetically evolved social learning biases, according to Henrich, open the door to religious beliefs because they can override our direct experiences and personal incentives (Henrich and McElreath, 2007). If prestigious leaders credibly signal their beliefs about the supernatural, even in the absence of personal experience, their authority can override intuitions that conflict with the content of their testimony (Henrich, 2009), as can their plausible-seeming magical practices that are subjectively appealing (Singh, 2018). Indeed, people often outsource so much of their knowledge that they do not know how much they do not know (Rozenblit and Keil, 2002).

We found some support for this view in our cross-cultural study of experts and knowledge specialists: many specialists were prestigious teachers, especially in task domains involving motor skills applied to everyday problems, such as toolmaking and food preparation (Lightner et al. 
2021b). See 'Prestigious teachers' in Figure 1. Similarly, in one of the few studies to investigate prestige-biased social learning in a relatively egalitarian society, Garfield and Hagen (2020) found that among Chabu forager-horticulturalists, biased-social learning was at least moderately associated with being an elected community leader and strongly associated with being widely respected in the community.

Our faith, though, is not blind. Learners are epistemically vigilant (Mercier and Sperber, 2017): When the consequences of a persuasive argument are personally relevant to recipients, they critically evaluate the argument based on its content (Axsom et al., 1987, Petty et al. 1981$)$. When the stakes are especially high, or where conflicts of interests exist, people remain largely skeptical about advice from even prestigious and well-respected members of their communities, and are wary of trusting advice that might not stand to benefit them personally (Morin, 2016, Lightner and Hagen, 2021a).

Learners' epistemic vigilance likely complements the social cues that Henrich and others have emphasized, such as prestige, but it also suggests that human "faith instincts" do not deviate far from personal incentives (Hagen and Hammerstein, 2006). In smaller-scale societies and informal group contexts, which lack strong institutionalized leadership, individuals are continually updating their cognitive models of candidate leaders, sharing information on their capacities and past performance, and evaluating efficacy of their social influence (Garfield et al., 2021). Reputations and social status may often be necessary but insufficient qualities of leadership; equally important are capacities - including supernatural, social, cognitive, and physical - to reliably produce individual and group benefits, and appropriately impose costs (Garfield et al., 2020). The ethnographic record does, however, provide ample evidence of reputations promoting conformity and group unity, in support of Henrich and cultural group selection arguments (e.g., Richerson et al., 2016; Smith 2020). Drawing on ethnographic data from 153 mostly nonindustrial societies, Garfield et al. (2021) suggest reputations for cultural group unity will be a context-independent human universal, likely to be found in all human societies, whereas reputations associated with social status and dominance, although fairly common across societies, are more likely to be context-dependent features of human reputations.

Cognitive bugs are the second ingredient needed to explain how moralizing gods enforce largescale collective actions. Few evolutionary theorists of religion doubt that supernatural beliefs are somehow rooted in adaptive cognitive mechanisms whose evolved functions were not "religious." Henrich favors the view that "supernatural" beliefs reflect an overuse of our otherwise practical abilities to mentalize (i.e., infer the mental states of others), creating an opportunity for cultural evolution to populate our worldviews with minds that do not exist. This is a compelling perspective, especially because assuming agency when stimuli are ambiguous can be an evolutionary "best bet" for minimizing costly decision-making errors (Guthrie, 1995).

We offer two caveats to these apparent cognitive bugs, however. First, mental representations of the supernatural might actually reflect abstract metaphors rather than sincere assumptions about reality. Lightner et al. (2021a) found that a traditional Maasai diviner characterized the mental properties of God (Engai) as more akin to the totality of knowledge rather than as an agent with its own active mental life, and many other cultures similarly describe their "supernatural agents" in indistinct and ethereal terms (Evans-Pritchard, 1956, Fuller, 2004, Bird-David, 1999). The extent to which these descriptions are metaphorical is a problem of interpretation that cannot be underestimated, particularly when ethnographers are interpreting their observations from a Western perspective (Sperber, 1985). We take this point up in more detail below.

A second caveat is that, to whatever extent we can (or cannot) characterize "supernatural" explanations as metaphorical abstractions, anthropomorphism can be a genuinely useful starting point for modeling rare and opaque phenomena, especially in domains where information is scarce and ambiguous (Lightner et al., 2021a). Misapplying the intentional stance might, in a literal sense, represent a distorted understanding of reality, but it can also be a useful falsehood for approximating the most relevant dynamics of a complex phenomenon (Keil, 2006, Lightner and Hagen, 2021b). 
To use some familiar examples, in modern biology, genes can be "selfish" agents with "goals" (Dawkins, 1976), societies can be likened to organisms (Richerson and Boyd, 1999), and cultural evolution can "seek out" cognitive glitches to "nurture" group-level harmony (p. 151). These are each a conventional shorthand that we recognize to be false, but they are useful for making predictions that would be difficult otherwise (Hammerstein and Hagen, 2006, Gardner, 2019). NonWEIRD explanations might similarly invoke useful anthropomorphic concepts to describe non-biotic physical processes: During a flash flood, observers might predict the water's movement across the landscape in terms of the water's goals, preferences, and spiteful disposition - a pragmatic and intuitive approach to making fitness-relevant predictions, no water spirits or similar ideas necessary.

By abstracting away many noisy details in our initial observations and creating cartoonishly simple models of reality - a skill our theories of mind are well-equipped to do - we improve a biasvariance tradeoff by approximating an underspecified model of complex and uncertain processes that are relevant to fitness (Gigerenzer and Brighton, 2009, Lightner and Hagen, 2021b). This type of usefully false explanatory model can be conditioned on future data, and therefore gains its utility because of its falsity (Wimsatt, 1987). Cross-culturally, starting from such a pragmatic and generalized explanation would equip future cultural learners with increasingly useful conventions for understanding their world. To paraphrase C. S. Peirce, this is about the best we can do in the face of complex real-world scenarios, most of which are opaque to the senses.

It is not obvious that supernatural beliefs are truly a glitch in our cognitive systems, as Henrich describes them, rather than useful abstractions about highly uncertain and complex observations. As a cognitive model, how should "the possible existence of supernatural beings, hidden powers, and parallel worlds" (p. 128) be differentiated from Westerners' models of consciousness, personality types, or probability theory and its use of counterfactual worlds? Empirically, Westerners and non-Westerners do frequently combine supernatural and natural concepts in their explanations of life, death, misfortune, meteorology, and disease (Legare et al., 2012, Tucker et al., 2015, Lightner et al. 2021a). For explaining illnesses in particular, the abundance of disease-causing spirits and magical contagion in the ethnographic literature can be matched by similar Western folk intuitions about germs and disease transmission, respectively (Keil et al., 1999, Gottlieb, 2004).

Among individuals, not all of these explanations are guaranteed to be equal, and some might even be unhelpful and misleading. This points to the importance of specialists who do provide falsehoods that are more useful than most - a dynamic we refer to as a market for specialists (Lightner et al., 2021b).

\section{Toward reconciling institutional vs. wild religions}

Leaders and knowledge specialist: 1 are central to both Henrich's institutional view of religion, as well as to the wild religions model which sees religious ideas as elements of broader explanatory systems for practical tasks (Bloch, 2008, Sperber, 2018, Boyer, 2020). For Henrich, prestigious teachers feed our faith instincts. For the wild religion scholars, knowledge specialists provide solutions to everyday problems to their clients. Our work has revealed an important distinction in the problem domains tackled by knowledge specialists that points toward a synthesis of these ideas.

Our analyses of the ethnographic record of knowledge specialists found one important cluster of cases, which we term 'prestigious teachers', that largely corresponds to Henrich's model. Broadly, and across different types of expertise, prestigious teachers tend to be skilled in common everyday tasks that involve observable motor activity, such as technology and food preparation (Lightner et al. 2021b). In smaller scale societies in particular, these skills are probably most commonly

\footnotetext{
1 "Knowledge specialists" refer to experts who possess high levels of conceptual knowledge in folk scientific domains, such as ethnobotany, ethnozoology, and ethnometeorology. See Lightner et al. (2021b) for details about our operationalization.
} 
learned during adolescence and via oblique modes, or from specialists other than parents (Garfield et al. 2016).

There is another large cluster of ethnographic cases, however, which we term 'efficacious healers', that better supports the wild religions view. These specialists often employ supernatural theories of disease and are in leadership roles, and therefore might be mistaken for religious leaders. However, they provide solutions to uncommon, serious, and uncertain problems. Their relationships with their clients are frequently transactional, and depend on how effective the specialists are at providing beneficial services. Often, and contrary to Henrich's model, their knowledge is proprietary - the specialists provides services, such as treatments for illnesses, to clients in return for payments, but keep the underlying knowledge systems to themselves. Winkleman (1986) similarly found that religious specialists, such as shamans, belonged to a broader "healer complex", i.e., medicinal specialists who administer herbal medicines to their clients. 


\section{A cross-cultural taxonomy of medicinal specialists}

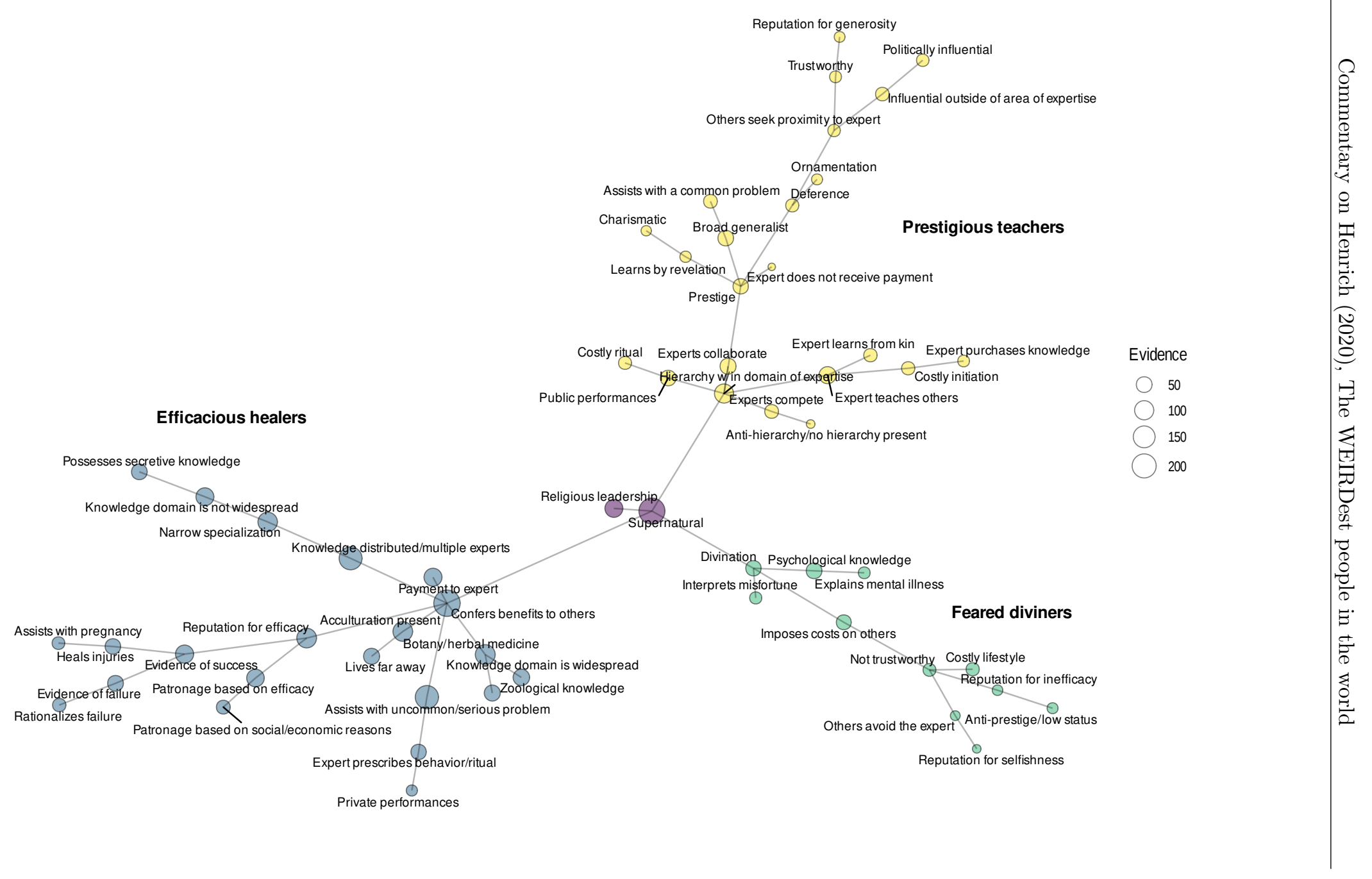

Figure 1: A data-driven taxonomy of ethnomedical specialists in 47 cultures derived from ethnographic text records in the Human Relations Area Files. This minimum spanning tree estimates the similarities of binary presence/absence data for each of the coded variables (vertices) in the cross-cultural dataset. Vertex sizes correspond to levels of text record evidence for each variable. Edge lengths represent binary distances between variables. Colors refer to our interpretations of each branch in the taxonomy of ethnomedical specialists. Adapted from Lightner et al. (2021a). 
We hypothesize that prestigious teachers are associated with common and observable tasks, such as tool-making and subsistence, because most adults need and use these skills, sometimes on a daily basis. The skills are widespread in the population and usually motor-based, so it is straightforward to acquire them by observation. Efficacious healers, in contrast, help with rare and unobservable problems, such as treating uncommon illnesses, because although most individuals might never need to solve this specific type of problem, someone in the population will. This creates a market for specialists who offer their services, based on valuable know-how that is difficult to copy, in exchange for various types of transactional payments (Lightner et al., 2021b).

While our findings clearly support some aspects of Henrich's model of religions and their underlying ingredients, they are problematic in cases where pragmatic specialist-client relationships are mistaken for religious communities. In some cases, to solve common collective action problems, political leaders such as priests might deploy the supernatural sticks and carrots Henrich describes. Across a diverse ethnographic sample of 59 cultures, leaders were found to have both supernatural qualities and perform ritual functions in over $60 \%$ of societies. Shaman leaders used their knowledge to impose costs on others (Garfield et al. 2020). While religious intuitions may drive much of social change, it is likely individual leaders and other influential individuals are at the helm.

In other cases, however, non-WEIRD "coreligionists" might in fact be clients who share patronage with the same pragmatic specialists who provide solutions to less common problems, such as illnesses, rather than as members of a community with a stable doctrine $(\overline{B o y e r}, 2020)$. Where this applies, it would be difficult to see how their "religious" beliefs - beliefs about the useful techniques of their specialist - are sufficiently uniform, widespread, or potent in motivating behavior for mobilizing collective action.

\section{Religions: How WEIRD are they?}

Henrich's view of religions as distinct, formal social institutions represents only some of the evidence on "religions" across cultures. Knowledge specialists who help clients are widespread in the ethnographic record. Their practical services can be misconstrued as religious rituals, and their abstract explanations as doctrinal beliefs in the supernatural. But why should specialists and their explanatory systems for solving practical problems be so reliably misconstrued as religious institutions in the first place?

The answer to this question, we suggest, is indirectly supplied by Henrich's book: Theories about what religions are and why they are useful are rooted in WEIRD assumptions about the religion concept. Evolutionary theories of religion, which we addressed in section 2, focus on individuals' beliefs and intentions, their commitments to the ingroup, and - perhaps most importantly - the assumption that people deeply care about what their gods care about. These theoretical emphases bear a striking resemblance to WEIRD religions because they "place individuals' personal commitments and their relationship with the divine at the core of spiritual life" (p. 415). Could the very concept of religion be WEIRD?

Christianity was and remains a major influence on the West. It is plausible, however, that this deep religious influence might not reflect a universal institution of religion. Rather, WEIRD observers might misinterpret non-WEIRD practices as evidence of religious institutions where no such thing exists (Sperber, 1985, Bloch, 2008, Boyer, 2016). Our results do not lead us to take such an extreme view, but they do give us pause about the assumption that religious institutions and their culturally evolved functions can always be assumed using the ingredients Henrich provides, or that they are a universal launchpad for human societies. In many cases, they might actually reflect useful services from leaders and knowledgeable specialists (Hagen and Garfield, 2019, Lightner et al. 2021a).

Grand theories are always wrong, but in a good way: like the explanations that knowledge specialists have offered for millennia, they engage physical, design, and intentional stances (Dennett 
1987) to varying degrees, retaining some particular details of the phenomenon of interest, but to approach the truth, ruthlessly ignoring or abstracting away the rest. Henrich's WEIRD concept has drawn the attention of science to humanity as a complex whole, and by so doing is helping restore the relevance of cultural anthropology. And Henrich is surely correct that the WEIRDness of Christianity is the right place to look to understand the weirdness of the West.

\section{Acknowledgements}

Aaron D. Lightner and Edward H. Hagen acknowledge financial support from the Issachar Fund and the Templeton Religion Trust. Zachary H. Garfield acknowledges IAST funding from the French National Research Agency (ANR) under the Investments for the Future (Investissements d'Avenir) program, grant ANR-17-EURE-0010. Partial funding by National Science Foundation Division of Behavioral and Cognitive Sciences awards \#1628509 and \#1823324.

\section{References}

Axsom, D., Yates, S., and Chaiken, S. (1987). Audience response as a heuristic cue in persuasion. Journal of personality and social psychology, 53(1):30.

Bird-David, N. (1999). "Animism" revisited: personhood, environment, and relational epistemology. Current anthropology, 40(S1):S67-S91.

Bloch, M. (2008). Why religion is nothing special but is central. Philosophical transactions of The Royal Society B: biological sciences, 363(1499):2055-2061.

Boyer, P. (2016). Explaining religious concepts: Lévi-strauss the brilliant and problematic ancestor. In Mental Culture, pages 174-185. Routledge.

Boyer, P. (2020). Informal religious activity outside hegemonic religions: Wild traditions and their relevance to evolutionary models. Religion, Brain \& Behavior, 10(4):459-472.

Dawkins, R. (1976). The selfish gene. Oxford Univ. Press, Oxford. OCLC: 477132640.

Dennett, D. C. (1987). The intentional stance. MIT press.

Diamond, J. (1997). Guns, Germs, and Steel. W. W. Norton, New York.

Evans-Pritchard, E. E. (1956). Nuer Religion. Nuer religion. Oxford Univ Press, New York.

Fuller, C. J. (2004). The camphor flame: Popular Hinduism and society in India. Princeton University Press.

Gardner, A. (2019). The agent concept is a scientific tool. Metascience, 28(3):359-363.

Garfield, Z. H., Garfield, M. J., and Hewlett, B. S. (2016). A Cross-Cultural Analysis of HunterGatherer Social Learning. In Hewlett, B. S. and Hideaki, T., editors, Social Learning and Innovation in Contemporary Hunter-Gatherers, Replacement of Neanderthals by Modern Humans Series, pages 19-34. Springer.

Garfield, Z. H. and Hagen, E. H. (2020). Investigating evolutionary models of leadership among recently settled Ethiopian hunter-gatherers. Special issue on Evolution and Biology of Leadership, 31(2):101290. 
Garfield, Z. H., Hubbard, Robert, H., and Hagen, E. H. (2019). Evolutionary models of leadership: Tests and synthesis. Human Nature, 30(1):23-58.

Garfield, Z. H., Schacht, R., Post, E. R., Ingram, D., and Macfarlan, S. J. (2021). zhgarfield/contentand-structure-of-reputation- domains: Preprint manuscript of the publication "The content and structure of reputation domains across human societies: a view from the evolutionary social sciences".

Garfield, Z. H., Syme, K. L., and Hagen, E. H. (2020). Universal and variable leadership dimensions across human societies. Evolution and Human Behavior, 41(5):397-414.

Gigerenzer, G. and Brighton, H. (2009). Homo heuristicus: Why biased minds make better inferences. Topics in cognitive science, 1(1):107-143.

Gottlieb, A. (2004). The Afterlife Is Where We Come From: The Culture of Infancy in West Africa. University of Chicago Press, Chicago, 1st edition edition.

Guthrie, S. (1995). Faces in the clouds: A new theory of religion. Oxford University Press on Demand.

Hagen, E. H. and Garfield, Z. (2019). Leadership and prestige, mothering, sexual selection, and encephalization: The computational services model.

Hagen, E. H. and Hammerstein, P. (2006). Game theory and human evolution: A critique of some recent interpretations of experimental games. Theoretical Population Biology, 69(3):339-348.

Hammerstein, P. and Hagen, E. H. (2006). Broken cogs or strategic agents? Science, 312(5773):530.

Henrich, J. (2009). The evolution of costly displays, cooperation and religion:: Credibility enhancing displays and their implications for cultural evolution. Evolution and Human Behavior, 30:244260.

Henrich, J. and Boyd, R. (1998). The Evolution of Conformist Transmission and the Emergence of Between-Group Differences. Evolution and Human Behavior, 19(4):215-241.

Henrich, J. and Gil-White, F. J. (2001). The evolution of prestige: Freely conferred deference as a mechanism for enhancing the benefits of cultural transmission. Evolution and Human Behavior, 22(3):165-196.

Henrich, J. and McElreath, R. (2007). Dual-inheritance theory: The evolution of human cultural capacities and cultural evolution. In Barrett, L. and Dunbar, R., editors, Oxford Handbook of Evolutionary Psychology.

Keil, F. C. (2006). Explanation and understanding. Annu. Rev. Psychol., 57:227-254.

Keil, F. C., Levin, D. T., Richman, B. A., and Gutheil, G. (1999). Mechanism and explanation in the development of biological thought: The case of disease. In Folkbiology, pages 285-319. The MIT Press, Cambridge, MA, US.

Kroeber, A. L. (1917). The superorganic. American Anthropologist, 19:163-213.

Legare, C. H., Evans, E. M., Rosengren, K. S., and Harris, P. L. (2012). The coexistence of natural and supernatural explanations across cultures and development. Child Development, 83(3):779793. 
Lightner, A. D. and Hagen, E. H. (2021a). Acculturation and market integration are associated with greater trust among Tanzanian Maasai pastoralists. Evolutionary Human Sciences, pages $1-33$.

Lightner, A. D. and Hagen, E. H. (2021b). Supernatural beliefs as adaptive explanations about the abstract and the otherwise mysterious. Unpublished manuscript.

Lightner, A. D., Heckelsmiller, C., and Hagen, E. H. (2021a). Ethnomedical specialists and their supernatural theories of disease. Review of Philosophy and Psychology.

Lightner, A. D., Heckelsmiller, C., and Hagen, E. H. (2021b). Ethnoscientific expertise and knowledge specialisation in 55 traditional cultures. Evolutionary Human Sciences (under review).

Mercier, H. and Sperber, D. (2017). The enigma of reason. Harvard University Press.

Morin, O. (2016). How traditions live and die. Oxford University Press.

Petty, R. E., Cacioppo, J. T., and Goldman, R. (1981). Personal involvement as a determinant of argument-based persuasion. Journal of personality and social psychology, 41(5):847.

Richerson, P., Baldini, R., Bell, A. V., Demps, K., Frost, K., Hillis, V., Mathew, S., Newton, E. K., Naar, N., and Newson, L. (2016). Cultural group selection plays an essential role in explaining human cooperation: A sketch of the evidence. Behavioral and Brain Sciences, 39.

Richerson, P. J. and Boyd, R. (1999). Complex societies: The evolutionary origins of a crude superorganism. Human Nature, 10(3):253-289.

Richerson, P. J. and Boyd, R. (2008). Not by genes alone: How culture transformed human evolution. University of Chicago press.

Rozenblit, L. and Keil, F. (2002). The misunderstood limits of folk science: An illusion of explanatory depth. Cognitive science, 26(5):521-562.

Singh, M. (2018). The cultural evolution of shamanism. The Behavioral and brain sciences, 2017:183.

Smith, D. (2020). Cultural group selection and human cooperation: a conceptual and empirical review. Evolutionary Human Sciences, 2.

Sperber, D. (1985). On Anthropological Knowledge. Cambridge University Press.

Sperber, D. (2018). Cutting culture at the joints? Religion, Brain \& Behavior, 8(4).

Spiro, M. (1992). Cultural relativism and the future of anthropology. In Marcus, G. E., editor, Rereading cultural anthropology, pages 124-151. Duke University Press.

Tucker, B., Tombo, J., Hajasoa, P., Nagnisaha, C., et al. (2015). Ecological and cosmological coexistence thinking in a hypervariable environment: Causal models of economic success and failure among farmers, foragers, and fishermen of southwestern Madagascar. Frontiers in psychology, $6: 1533$.

Wimsatt, W. C. (1987). False models as means to truer theories. Neutral models in biology, pages $23-55$. 